\title{
Investigation on the Effect of Crack Length on Mechanical Properties of Functionally Graded Materials
}

\author{
Gang Chen ${ }^{1, a}$; Xiyu Zhao ${ }^{2, b}$ and Pengcheng Zhai ${ }^{3, c}$ \\ ${ }^{1,3}$ School of Science, Wuhan University of Technology, Wuhan 430070, China \\ ${ }^{2}$ Institute of Mechanics, Chinese Academy of Sciences, Beijing 100080, China \\ ${ }^{a}$ cg_chen@whut.edu.cn, benjoyzxy@yahoo.com.cn, cpczhai@126.com
}

Keywords: Functionally Graded Materials, Thermal Barrier Coating, Creep, Stress Intensity Factor, Finite Element Method

\begin{abstract}
In this article, the thermo-mechanical responses of ceramic/metal functionally graded thermal barrier coating(TBC) in work environment are analyzed by a finite element method. Both the crack-tip field and the stress intensity factor of functionally graded TBC are analyzed and calculated. It is discussed that the effect of crack length on mechanical properties of functionally graded TBC in the condition creep and no creep of pure metal. The numerical results indicate that the effect of crack length $(\mathrm{a} / \mathrm{t})$ is negligible to temperature distributions and the maximum displacements of whole model but remarkable to the 1st principal stress and stress intensity factor of crack region. Moreover, creep phenomenon of pure metal can relax the value of displacement, stress and stress intensity factor but do not alter their distribution.
\end{abstract}

\section{Introduction}

The concept of functionally graded materials (FGMs) has been introduced in material design for many application fields to eliminate stress concentrations, relax residual stresses, and enhance bonding strength. In designing of FGMs, it is important to consider imperfections, such as cracks, which are often pre-existed or generated by external loads during service. The creep behavior of FGMs will appear under high temperature environment.

Several review articles have been written on FGMs, covering applications [1], processing [2], modelling [3,4] and fracture mechanics [5,6]. Wiliamson et al[7] studied the influence of the creep phenomenon on the residual stress of the $\mathrm{Al}_{2} \mathrm{O}_{3} / \mathrm{Ni}$ FGMs by finite element analysis. The numerical results have shown that influence of the creep phenomenon on the residual stress was slightly but the deformation of the materials was obviously effected by the creep phenomenon. Further research works indicate that the fracture and fatigue of FGMs is related to the creep phenomenon. For example, Ali et al [8] simulated the thermal cycling load process for functionally graded TBC by FEM analysis. They found that the possibility of micro crack initiation at the interface increased while the creep was taken into account. Pindera et al [9] used the higher-order theory for FGMs to study the spallation mechanism of functionally graded $\mathrm{TBC}$ under thermal loading. Their experimental and numerical results indicated that the creep phenomenon had an obvious effect on the thermal stress distribution and the fracture of the materials. Zhou et al $[10,11]$ discussed the effect of the high temperature creep phenomenon on the residual stresses and crack driving force. The results mentioned above indicated that the creep phenomenon was important and cannot be neglected.

The present study aims to discuss that the effect of crack length on mechanical properties of functionally graded TBC in the condition creep and no creep of pure metal. The thermo-mechanical responses of ceramic/metal functionally graded TBC in work environment are analyzed by finite element method. Both the crack-tip field and the stress intensity factor of functionally graded TBC are analyzed and calculated. The creep phenomenon of the metal and the vertical crack of pure ceramic(PSZ) layer are taken into account, and relevant numerical results are obtained. 


\section{Problem Description and Material Model}

In this work, the functionally graded partially stabilized zirconia (PSZ)/NiCrAlY bond coat alloy TBC studied in this article are fabricated by the low pressure plasma spray (LPPS) technique. The coating architecture, which consists of six layers including pure ceramic(PSZ), 25 vol. \% NiCrAlY interlayer, 50 vol. \% NiCrAlY interlayer, 75 vol. \% NiCrAlY interlayer, NiCrAlY layer and the substrate, is shown in Fig.1.
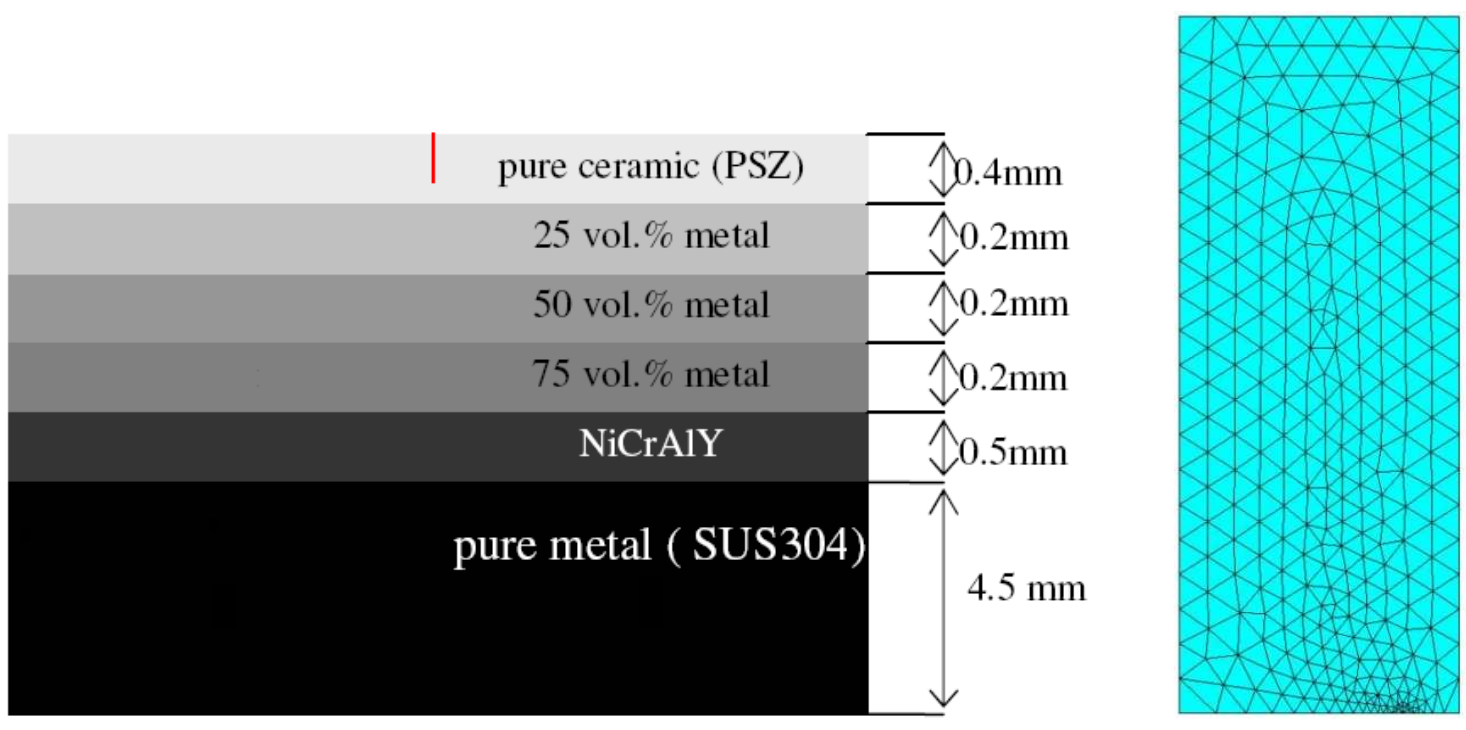

Fig.1 TBC architecture

Fig. 2 FE grid (crack region)

Table 1: Properties of PSZ, NiCrAlY and SUS304.

\begin{tabular}{|c|c|c|c|c|c|c|c|c|}
\hline \multirow{3}{*}{$\begin{array}{l}\text { Thermal Conductivity } \\
{\left[10^{-7} \mathrm{kcal} / \mathrm{mms}^{\circ} \mathrm{C}\right]}\end{array}$} & \multicolumn{4}{|c|}{ PSZ } & \multicolumn{3}{|c|}{ NiCrAlY } & SUS304 \\
\hline & $10^{\circ} \mathrm{C}$ & $1079^{\circ} \mathrm{C}$ & $1497^{\circ} \mathrm{C}$ & $1800^{\circ} \mathrm{C}$ & $10^{\circ} \mathrm{C}$ & $1079^{\circ} \mathrm{C}$ & $1497^{\circ} \mathrm{C}$ & \multirow{2}{*}{39.402} \\
\hline & 1.722 & 5.158 & 6.519 & 7.490 & 13.779 & 39.641 & 49.67 & \\
\hline \multirow{2}{*}{$\begin{array}{l}\text { Specific Heat } \\
{\left[\mathrm{kcal} / \mathrm{kg}^{\circ} \mathrm{C}\right]}\end{array}$} & $10^{\circ} \mathrm{C}$ & $1094^{\circ} \mathrm{C}$ & $1497^{\circ} \mathrm{C}$ & $1800^{\circ} \mathrm{C}$ & $10^{\circ} \mathrm{C}$ & $1094^{\circ} \mathrm{C}$ & $1497^{\circ} \mathrm{C}$ & \multirow{2}{*}{0.1218} \\
\hline & 0.117 & 0.16 & 0.176 & 0.1879 & 0.0979 & 0.17 & 0.1896 & \\
\hline Density $\left[10^{-6} \mathrm{~kg} / \mathrm{mm}^{3}\right]$ & \multicolumn{4}{|c|}{5.67} & \multicolumn{3}{|c|}{6.98} & 7.86 \\
\hline \multirow{2}{*}{$\begin{array}{l}\text { Thermal Expansion } \\
\text { Coefficient }\left[10^{-6} /{ }^{\circ} \mathrm{C}\right]\end{array}$} & $100^{\circ} \mathrm{C}$ & $400^{\circ} \mathrm{C}$ & $600^{\circ} \mathrm{C}$ & $1800^{\circ} \mathrm{C}$ & $100^{\circ} \mathrm{C}$ & $600^{\circ} \mathrm{C}$ & $1500^{\circ} \mathrm{C}$ & \multirow{2}{*}{16.4} \\
\hline & 9.75 & 10.7 & 10.9 & 10.7 & 12.5 & 15.7 & 17.5 & \\
\hline $\begin{array}{l}\text { Young's Modulus } \\
{[\mathrm{GPa}]}\end{array}$ & \multicolumn{4}{|c|}{$\begin{array}{c}18.38-0.00566 \mathrm{~T} \\
\mathrm{~T} \text { in }{ }^{\circ} \mathrm{C}\end{array}$} & \multicolumn{3}{|c|}{$\begin{array}{c}196.13-0.07383 \mathrm{~T} \\
\mathrm{~T} \text { in }{ }^{\circ} \mathrm{C}\end{array}$} & $\begin{array}{c}186.41-0.057 \mathrm{~T} \\
\mathrm{~T} \text { in }{ }^{\circ} \mathrm{C}\end{array}$ \\
\hline Poisson Ratio & \multicolumn{4}{|c|}{0.076} & \multicolumn{3}{|c|}{$\begin{array}{c}0.3+5.8636 \times 10^{-5} \mathrm{~T} \\
\mathrm{~T} \text { in }{ }^{\circ} \mathrm{C}\end{array}$} & 0.3 \\
\hline
\end{tabular}

The fixed temperature, which is $1500 \mathrm{~K}$, is applied on the PSZ surface. The substrate surface is simulated as an ambient boundary. The ambient temperature is $400 \mathrm{~K}$. The initial temperature is assumed to $300 \mathrm{~K}$, and the reference temperature (that's stress-free temperature) is assumed to $300 \mathrm{~K}$ too. Simply supported beam is considered as the calculation model, and the plane stress model for the finite element analysis is utilized. The finite element grid of crack region is given in Fig.2.

Properties of PSZ, NiCrAlY and SUS304, which are listed in Table 1, are excerpted from the 
literature [12]. Moreover, properties of the functionally graded TBC on special temperature are calculated by linear interpolation. In the present study, the influence of the temperature on materials' properties is neglected to simplify the problem. The vertical crack is prefabricated in pure ceramic(PSZ) layer. The thermo-mechanical responses of ceramic/metal functionally graded TBC in work environment are analyzed by finite element method.

\section{Numerical Results and Discussion}

The vertical crack of pure ceramic(PSZ) layer in calculation model are taken into account, and the effect of crack length on mechanical properties of functionally graded TBC is discussed. The crack length $(\mathrm{a} / \mathrm{t})$ of dimensionless is used in result discussion, and $\mathrm{t}$ is the thickness of pure ceramic(PSZ) layer.

The temperature distributions of the functionally graded TBC along the thickness direction for different crack length are given in Fig.3. From Fig.3, temperature distribution of each material layer is linear, but temperature arise a break in the interface of TBC and substrate caused by the different thermal conductivity of materials. It is seen that the temperature distribution curves are almost overlapped for different crack length $(\mathrm{a} / \mathrm{t})$. The maximum displacements of the functionally graded TBC for different crack length $(\mathrm{a} / \mathrm{t})$ are presented in Fig.4, and the displacement values are almost equal. From Figs.3 and 4, the results indicate effect of crack length $(\mathrm{a} / \mathrm{t})$ on temperature distributions and the maximum displacements is negligible.
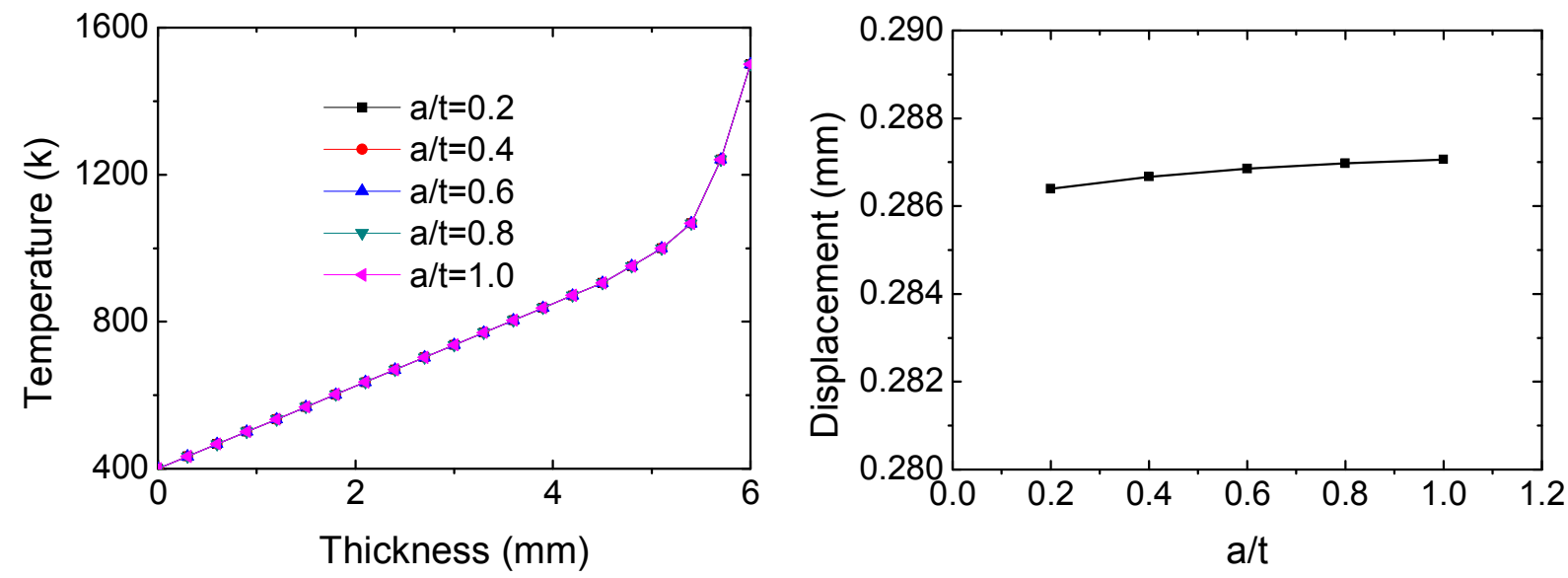

Fig.3 Effect of a/t on temperature distribution Fig.4 Effect of $a / t$ on the maximum displacement

The distribution contour of 1st principal stress in crack region are given in Fig.5. From Fig.5, the maximum stress is $575.2 \mathrm{MPa}$ and $473.0 \mathrm{MPa}$ when the crack length $(\mathrm{a} / \mathrm{t})$ is 0.6 and 0.8 , and the stress singularity is very obvious in crack-tip stress fields. The crack-tip stress singularity is the same in functionally graded TBC as in homogeneous materials.

Effect of the crack length $(\mathrm{a} / \mathrm{t})$ on the 1 st principal stress and stress intensity factor of crack region are presented in Fig.6 and Fig.7, respectively. The 1st principal stress of crack region is different for different crack length $(\mathrm{a} / \mathrm{t})$, and the difference is large. The 1 st principal stress is the maximum when the crack length $(\mathrm{a} / \mathrm{t})$ is 0.6 . The stress intensity factor is first increased and then decreased, and the maximum value is 48.6 when the crack length $(\mathrm{a} / \mathrm{t})$ is 0.8 . In other words, the stress intensity factor of crack region is increased along with the increase of crack length $(\mathrm{a} / \mathrm{t})$ except interface crack. The results indicate effect of crack length $(\mathrm{a} / \mathrm{t})$ on the 1 st principal stress and stress intensity factor of crack region is obvious, and the increase of crack length(a/t) easily cause failure of the functionally graded TBC. 


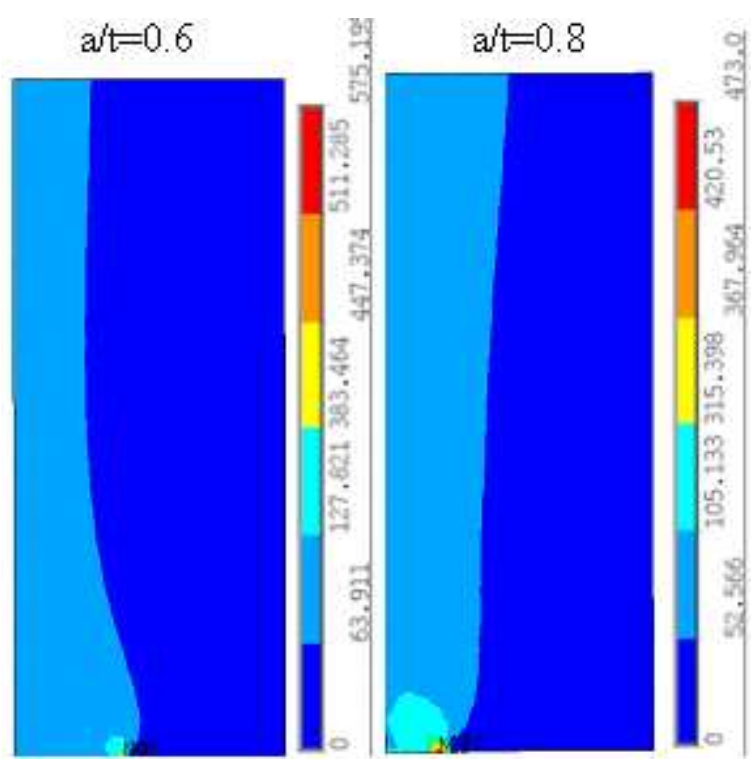

Fig.5 1st principal stress distribution of crack region

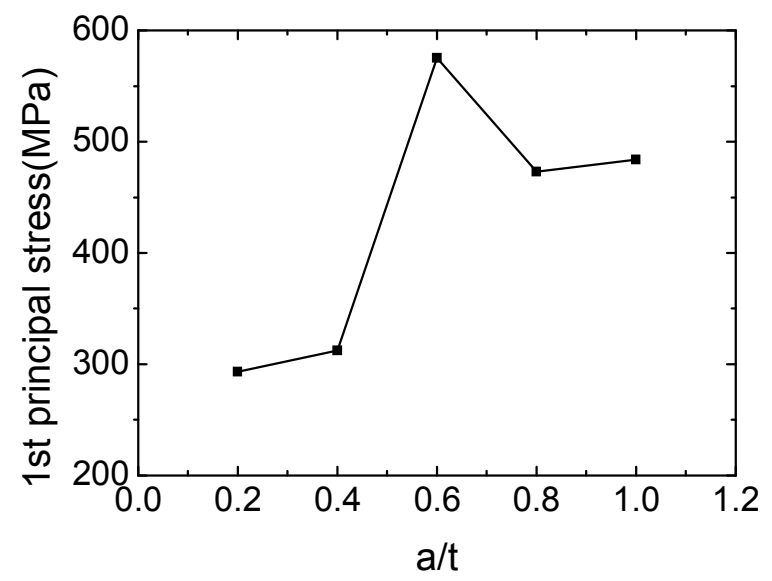

Fig. 6 Effect of $a / t$ on the 1 st principal stress
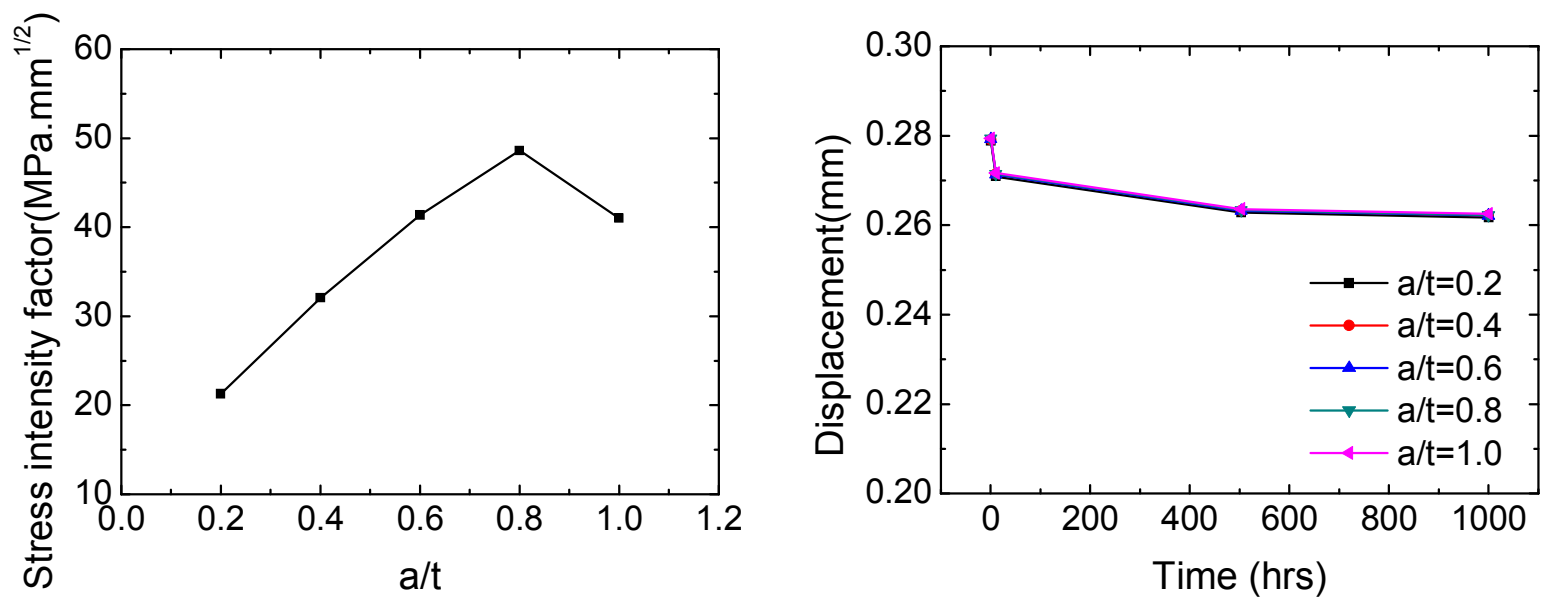

Fig.7 Effect of a/t on stress intensity factor

Fig. 8 Effect of $\mathrm{a} / \mathrm{t}$ on the displacement histories

The creep properties of pure metal layer in calculation model are taken into account, and the effect of crack length $(\mathrm{a} / \mathrm{t})$ on mechanical properties of functionally graded TBC is discussed. The displacement histories of the functionally graded TBC for different crack length $(\mathrm{a} / \mathrm{t})$ are plotted in Fig.8. From Fig.8, the displacement values of functionally graded TBC are almost equal for different crack length $(\mathrm{a} / \mathrm{t})$ and gradually descend along with the increase of service time.

Effect of crack length(a/t) on the 1st principal stress histories and stress intensity factor histories of crack region are presented in Fig.9 and Fig.10, respectively. The 1st principal stress and stress intensity factor of crack region is large difference for different crack length(a/t), and also descend along with the increase of service time. The results indicate creep phenomenon of pure metal layer can relax the value of displacement, stress and stress intensity factor but do not alter their distribution. 


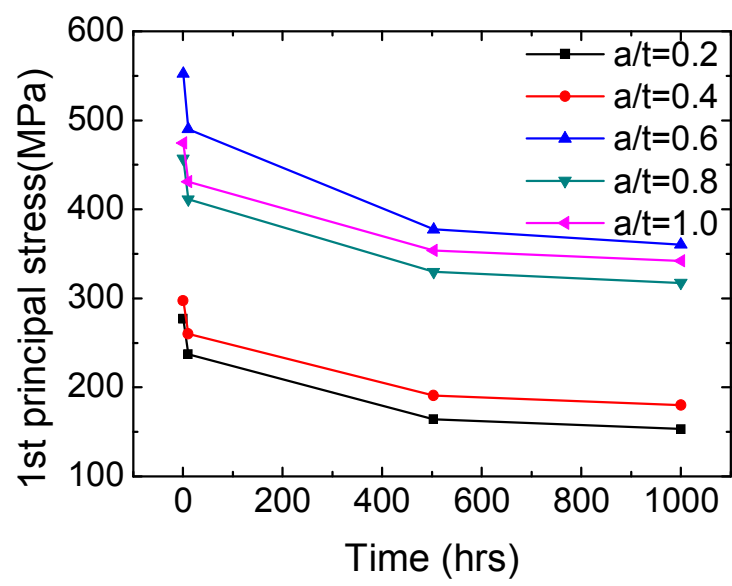

Fig.9 Effect of a/t on 1st principal stress histories

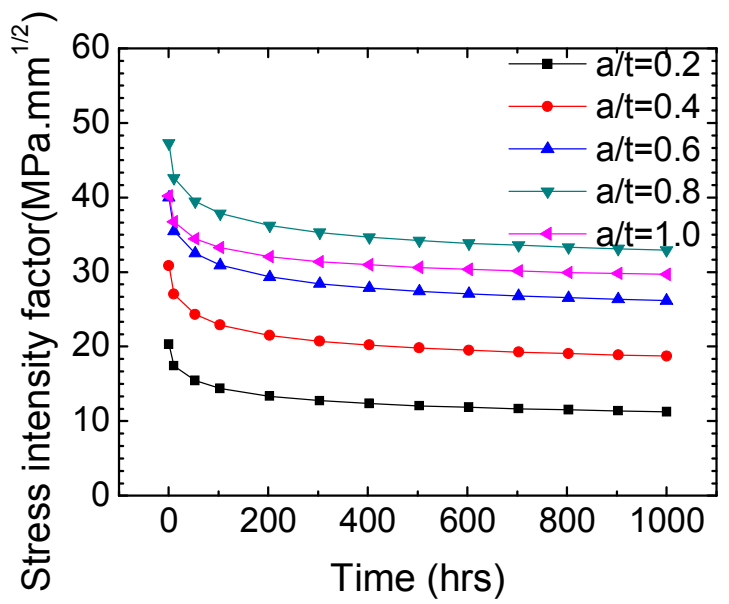

Fig.10 Effect of $\mathrm{a} / \mathrm{t}$ on stress intensity factor histories

\section{Summary}

In this article, the thermo-mechanical responses of ceramic/metal functionally graded TBC in work environment are analyzed by finite element method. The creep phenomenon of the metal and the vertical crack of pure ceramic(PSZ) layer are taken into account, and it is discussed that the effect of crack length on mechanical properties of functionally graded TBC.

According to the numerical results of the present work, it should be noted that the stress singularity is very obvious in crack-tip stress fields, and the effect of crack length $(\mathrm{a} / \mathrm{t})$ is negligible to temperature distributions and the maximum displacements of whole model but remarkable to the 1 st principal stress and stress intensity factor of crack region. Moreover, creep phenomenon of pure metal can relax the value of displacement, stress and stress intensity factor but do not alter their distribution.

\section{Acknowledgement}

Financially supported by Fundamental Research Funds for Central Universities(2010-1a-021).

\section{References}

[1] N. Cherradi, A. Kawasaki, M. Gasik: Compos Eng, Vol.4(1994), p.883.

[2] A. Mortensen, S. Suresh: Int Mater Rev, Vol.40(1995), p.239.

[3] A.J. Markworth, K.S. Ramesh, W.P. Parks: J Mater Sci, Vol.30(1995), p.2183.

[4] T. Hirano, K. Wakashima: MRS Bull, Vol.20(1995), p.40.

[5] F. Erdogan: Mater Res Soc Bull, Vol.20(1995), p.43.

[6] F. Erdogan: Compos Eng, Vol.5(1995), p.753.

[7] R.L. Wiliamson, B.H. Rabin and G.E Byerly: Composites Engineering, Vol.5 (1995), p. 851.

[8] M.Y. Ali, S.Q. Nusier and G.M. Newaz: Inter. J. of Solids and Structures Vol.38 (2001), p.3329.

[9]M.J. Pindera, J. Aboudi and S.M. Arnold: Engineering Fracture Mechanics,Vol.69(2002), p.1587.

[10] Y.C. Zhou and T. Hashida: Inter. J. of Solids and Structures, Vol.38(2001), p.4235.

[11] Y.C. Zhou and T. Hashida: Inter. J. of Fatigue, Vol.24 (2002), p.407.

[12] Nippon Steel Technology Research (NSTR), Experimental report for the properties of $\mathrm{ZrO} 2 / \mathrm{Ni}$ FGM coating fabricated by LPPS, National Aerospace Lab., 1997 (in Japanese). 
Frontiers of Manufacturing and Design Science

10.4028/www.scientific.net/AMM.44-47

Investigation on the Effect of Crack Length on Mechanical Properties of Functionally Graded Materials

10.4028/www.scientific.net/AMM.44-47.2244 